\#099 Força de adesão de brackets ortodônticos a superfícies de compósito

Inês Longo*, Pedro Mariano Pereira, Luís Proença

Instituto Universitário Egas Moniz

Objetivos: Comparar a força de adesão de brackets ortodônticos a superfícies de resina composta, utilizando diferentes preparações de superfície, ácido ortofosfórico a 35\% e jato de óxido de alumínio $50 \mu \mathrm{m}$, e diferentes sistemas adesivos Transbond ${ }^{\mathrm{TM}}$ XT e Assure ${ }^{\circledR}$ Plus All. Materiais e métodos: Foram realizadas 48 faces vestibulares de pré-molares em resina composta Filtek ${ }^{\mathrm{TM}}$ $\mathrm{Z} 250$, que posteriormente foram envelhecidas recorrendo a 5.000 ciclos de termociclagem em água, em banhos alternados de $5^{\circ} \mathrm{C}$ e $55^{\circ} \mathrm{C}$. As amostras foram distribuídas aleatoriamente em quatro grupos, para colagem dos brackets ortodônticos de pré-molares Victory Series ${ }^{\mathrm{TM}}$ (3M Unitek), modificando o método de preparação de superfície e o sistema adesivo utilizado. No Grupo 1 a superfície de compósito foi preparada com ácido ortofosfórico a 35\% e foi utilizado o sistema adesivo Transbond ${ }^{\mathrm{TM}}$ XT, no Grupo 2 utilizou-se o ácido ortofosfórico a 35\% e o Assure ${ }^{\circledR}$ Plus All, no Grupo 3 utilizou-se jato de óxido de alumínio (50 $\mu \mathrm{m})$ e o TransbondTM XT e no Grupo 4 utilizou-se jato de óxido de alumínio com o Assure ${ }^{\circledR}$ Plus All. Realizou-se nova termociclagem, na qual as amostras foram sujeitas a 10.000 ciclos em água entre os $5^{\circ} \mathrm{C}$ e os $55^{\circ} \mathrm{C}$. De seguida, as amostras foram submetidas a testes de cisalhamento à velocidade de $1 \mathrm{~mm} / \mathrm{min}$. O local de falha da adesão foi determinado segundo o Índice de Remanescente Adesivo modificado. Para a análise estatística inferencial dos dados foram utilizados os testes ANOVA One-way e Kruskal-Wallis, sendo fixado um nível de significância de $5 \%(p<=0,05)$. Resultados: As forças médias de adesão obtidas nos quatro grupos foram de $7,1 \pm 1,4$ $\mathrm{MPa}, 6,7 \pm 2,0 \mathrm{MPa}$, 8,6 $\pm 1,1 \mathrm{MPa}$ e 8,8 $\pm 1,7 \mathrm{MPa}$, respetivamente, para os Grupos 1, 2, 3 e 4. Foram identificadas diferenças estatisticamente significativas entre o Grupo 2 e o Grupo 3 ( $p=0,028$ ), bem como entre o Grupo 2 e o Grupo 4, ( $p=0,014)$. Quanto ao Índice de Remanescente Adesivo modificado, não se verificaram diferenças estatisticamente significativas ( $p=0,283$ ), sendo que em $81,25 \%$ dos casos a falha de adesão ocorreu predominantemente na interface adesivo-bracket (score 2). Conclusões: A preparação de superfícies em resina composta com jato de óxido de alumínio, demonstrou ser o método mais eficaz, em ambos os sistemas adesivos estudados, para a adesão de brackets ortodônticos. http://doi.org/10.24873/j.rpemd.2022.01.956

\section{\#100 Volume do seio maxilar em doentes submetidos a tratamento ortodôntico-cirúrgico}

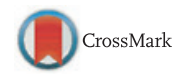

Raquel Travassos*, Mariana Serrazes, Francisco Caramelo, Maria João Rodrigues, Inês Francisco, Francisco Vale

Faculdade de Medicina da Universidade de Coimbra, Instituto de Ortodontia da Faculdade de Medicina da Universidade de Coimbra, Instituto de Oclusão e Dor Orofacial da Faculdade de Medicina da Universidade de Coimbra, Instituto de Investigação Clínica e Biomédica da Faculdade de Medicina da Universidade de Coimbra

Objetivos: Avaliar as alterações do volume dos seios maxilares após a cirurgia ortognática. Materiais e métodos: Este estudo retrospetivo incluiu 19 doentes ortodôntico-cirúrgicos submetidos a cirurgia ortognática com osteotomia de Le Fort I. A avaliação do volume do seio maxilar, pré-operatório (T0) e pós-operatório (T1), foi avaliado com recurso a tomografias computorizadas de feixe cónico no software ITK-SNAP. De forma averiguar o efeito do tratamento ortodôntico-cirúrgico no volume dos seios maxilares foi realizado o teste t-Student. Para explorar as possíveis diferenças entre sexos, recorreu-se ao teste t-Student para amostras independentes. A correlação entre os volumes pré e pós-operatório foi analisada através do coeficiente de correlação de Pearson. A concordância intraoperador foi avaliada pelo coeficiente de intra-classe (ICC). Consideraram-se estatisticamente significativos valores para $p<0,05$. Resultados: Não foram encontradas diferenças estatisticamente significativas entre o volume pré e pós-operatório dos seios maxilares ( $p>0,05$ ), embora se tenha verificado um aumento do volume pós-operatório do seio maxilar direito no sexo masculino $(p=0,037)$. Relativamente ao sexo feminino, não se verificaram diferenças estatisticamente significativas para ambos os seios maxilares $(p>0,005)$. A potência atingida na comparação de ambos os seios antes e após cirurgia foi de $8 \%$. A concordância intraoperador foi muito forte (ICC=0,974). Conclusões: O tratamento ortodôntico-cirúrgico realizado com a técnica de Le Fort I bem como o sexo do doente não influenciou o volume dos seios maxilares na amostra estudada. A tomografia computorizada de feixe cónico apresenta-se como uma ferramenta de diagnóstico para avaliação do volume dos seios maxilares, estando indicada sobretudo em doentes que apresentam patologia das vias aéreas superiores.

http://doi.org/10.24873/j.rpemd.2022.01.957

\#101 Morfologia dos tecidos moles de pacientes com ausência congénita de segundos pré-molares

Daniela Sousa*, Luís Jardim, Rui Pereira

Faculdade de Medicina Dentária da Universidade de Lisboa

Objetivos: Comparar a morfologia dos tecidos moles e dos tecidos duros de pacientes com agenesia congénita de segundos pré-molares com um grupo de controlo, sem agenesia. Materiais e métodos: A amostra total incluiu 66 jovens adultos caucasianos com idade entre 18 e 30 anos, selecionados aleatoriamente da base de dados de uma clínica especializada em Ortodontia em Lisboa. A amostra total foi composta por 2 grupos: 32 indivíduos com agenesia congénita de pelo menos um segundo pré-molar (Grupo Agenesia) e 34 indivíduos sem agenesia (Grupo Controlo). A análise cefalométrica das telerradiografias de perfil foi realizada com o programa Quick Ceph 2000. Um segundo traçado cefalométrico foi realizado de forma a calcular o erro aleatório através do coeficiente de correlação intraclasse para cada variável. A influência da agenesia sobre a morfologia dos tecidos moles foi avaliada comparando as variáveis cefalométricas através de testes t-Student para amostras independentes. A análise estatística foi feita com o programa IBM SPSS ${ }^{\circledR}$ e os resultados foram considerados estatisticamente significativos para $\mathrm{p}<0,05$. Resultados: A profundidade do Sulco Labial Inferior e o comprimento do Lábio Superior apresentaram-se significativamente reduzidas no Grupo Agenésia $(p<0,05)$. 